\title{
Multiple expectations; assessing the assumed roles of theory in relation to urban design
}

\begin{abstract}
Designers take different approaches when dealing with urban problems. Some find solutions in existing theories, some rely on their creativity, and many take a middle way. The questions here are what they expect from theory and how they follow their expectations. This article examines the ways in which theory is being applied within the field of urban design following on from recent discussions on this topic (Cuthbert, 2007; Biddulph, 2012; Marshall, 2012; Dovey \& Pafka, 2015; Marshall, 2016). The article then identifies four models for employing theory within urban design: as servant of innovation, as scientific formulation, as a means to control wicked problems, and finally as the subject for critique.

In a comparison, these four models are assessed in relation to their use within both design and research contexts. The final part of this article examines how urban design professionals employ theory in their work within practice and academia. The article concludes with examining the advantages and disadvantages of each model, and adds that being confined to one model of employing theory would exacerbate urban problems. Reflecting on the interviews, the article advocates multiple models be used, specifically chosen according to the problem in hand.
\end{abstract}




\section{Introduction: urban design theory - an area for disagreement}

Urban design (Madanipour, 1996) and theory (Bernstein, 1972) are both vague terms. Consequently, urban design theory is a vague concept from which different scholars derive different understandings. Nonetheless, discussion on urban design theory seems to have been flourishing during the last decade, implying the importance of the topic (Biddulph, 2012; Carmona, 2014; Cuthbert, 2007; Dovey \& Pafka, 2015; Marshall, 2012, 2016). This article starts with clarifying what is meant by urban design theory.

Following the method used by dictionaries when defining words, this article takes what is widely understood and conceptualized as urban design to be the correct definition of urban design. What is being understood as urban design is formed by seemingly controversial theoretical arguments (Carmona, 2014; Foroughmand Araabi, 2016). The main concern of the core body of urban design knowledge is to enhance the quality of the built environment. Also, the word theory, in regard to urban design, can be conceptualized in various ways. This article takes an affirmative approach and relies on a loose yet fundamental definition of theory. Theory is a set of statements that explains certain phenomena (Godfrey-Smith, 2003). Theory explains and provides a sense of understanding, therefore enabling explanations of past events and predicting future events to a certain degree. Thus, theory provides the professionals with the sense of control over certain phenomena (Reynolds, 2007). This definition of theory puts it at the heart of knowledge, in the sense that it is theory which makes sense of knowledge and makes it re-applicable.

Scanning the literature of urban design shows a disagreement over what is expected from urban design theory. Cuthbert argues that any theory must be falsifiablei. He adds that urban design theories must rely on socio-political studies in order fully to understand urban formation. Cuthbert criticises the existing condition of the literature as failing to have substantial theory in this respect (Cuthbert, 2007). Marshall, responding to Cuthbert, highlights scientific aspects of urban design theories, arguing that even those urban design theories which are testable are not being scientifically tested (Marshall, 2012). He also states that many attempts in theory are in fact pseudo-scientific. Dovey and Pafka (2015), responding to Marshall's article, argue that urban design theories are too complicated to be applied in a scientific manner. They argue that reducing urban knowledge to a certain set of criteria would harm the richness of theories; their example of such a richness is Jacobs' The Death and Life of Great American Cities (Jacobs, 1992).

This argument shows that there is a disagreement over the usage of theory in urban design that could be followed in a wider range of the literature. This disagreement refers to the idea of urban design theory in its totality and not to specific theories. The aforementioned scholars refer to theories as examples illustrating their point but their arguments go beyond those examples.

Reviewing the ongoing argument over the notion of urban design theory, this article suggests the aforementioned scholars have different expectations from theory. What scholars expect from theory comes prior to their considering the particular subject of the theory, as theories with different subjects of study can follow the same expectations. In turn, a certain expectation can be embodied in various subjects. In this regard, what scholars expect from theory is similar to a framework, or a mindset, that is rarely discussed.

This article identifies four major models of expectations from theory in urban design as servant of innovation, as scientific formulation, as a means to control wicked problems and as the subject for critique. Following this categorization, this article makes a call for more precise 
understanding and employment of each model. The last section examines the models used in real works of practitioners and academics, from which the article concludes that having a mix of expectations of theory is helpful, provided that an appropriate expectation is used in any given situation. This means despite the fact that different models are following different logics, professionals often mix them together. Following this conclusion, it is necessary to reflect this multiplicity of view in the education of urban design.

\section{Four models of different expectations from theory}

Scanning the field of urban design, four distinguishable expectations of theory are identified. These expectations appear to be at the philosophical level, preceding the subject of any given theory. In this regard, theories in each model may be normative/descriptive or look at different topics (Moudon, 1992). The distinguishing criterion for each model is what is assumed to be the role of theory.

\section{Theory as the servant of innovation}

The first model of expectation from theory is to take it as the servant of innovation. In this approach, theory is used to serve innovation. Cities are sites for innovation and new experiences. Innovative design can help cities in their competition with other cities (Banerjee \& Loukaitou-Sideris, 2011). Theory enhances the soundness of innovation and in cases assists its success. Expectedly, many radical designs take this model. When the designer or thinker first 'knows' what they want to do before referring to theory, this model is in use. Examples of an expectation of theory can be found in Futurists (Giedion, 2009), Archigram (Lynch, 1984) and many form-oriented urban projects.

This model may appear to be anti-theory, as the innovation dominates theory. Nevertheless, theory can be beneficial here in evaluating the creativity through theory and in communication. Theory can also be helpful as a resource, but innovation dominates in this model. When Jane Jacobs argues urban design is not a piece of art, she refers to this expectation of theory (Jacobs, 1992). Nonetheless, as was argued, these models are not about the subjects of theory. Marshall's article entitled The Kind of Art Urban Design is (Marshall, 2016), despite considering urban design as art, evidently follows a different expectation of theory; as is the case with Bentley (2002). Arguably theory for Marshall and Bentley aims to control wicked problems (see the third model below).

\section{Theory as scientific formulation}

In opposition to expecting theory to be the servant of innovation, urban design theory can be expected to function in a scientific manner. Scientific expectation of applying urban design theory requires research to pin down specific criteria and their corollary. There are examples of such an approach (Nasar, 1998; Weicher \& John, 1973). Moughtin suggests urban design process would follow scientific process (Moughtin, 2003, 2004). What is being advocated as scientific theory/method here mostly refers to systematically testing the theories. This conception follows a certain tradition in philosophy of science best presented by Karl Popper (Popper, 2008). For example, Cuthbert believed that urban design theories are not falsifiable, therefore not valid (Cuthbert, 2007). Marshall, Dovey and Pafka have a similar conception of science and scientific theory (Dovey \& Pafka, 2015; Marshall, 2012).

However, this conception of science is dominant in the philosophy of science. Philosophy of science has a history of contradicting trends of theory and scientific methods (Balashov \& Rosenberg, 2002; Curd \& Cover, 1998; Godfrey-Smith, 2003). More recent philosophers of science, examining the history of science, advocate that science does not follow any fixed methods. Rather, it creates a theory in an anarchistic way and employs it for as long as the theory appears to be useful (Feyerabend, 2002). This echoes what Dovey and Pakfa explain as abduction of theory in urban design. Yet as Feyerabend and Lakatos argue, this has always been the case in developing human 
knowledge (Feyerabend, 2011; Lakatos, 1980) and is not a characteristic of theory in a particular discipline or for a certain period of time.

Urban designers seem to neglect alternative conceptions of scientific theory. In this way, their expectations of scientific theory remain at the level of simply testing co-relationships between two sets of dependent and independent variants. Regardless of what science is and how theory functions in a scientific manner, there is a trend expecting the theory in urban design to be scientific.

\section{Theory as a means to control wicked problems}

Many changes in urban planning have been echoed in urban design arguments. Peter Hall argued that during the 1970s, the attempt to justify urban theories shifted towards social sciences (Hall, 2002). Considering the social aspects is what stimulated urban design to have a more complex understanding of urban problems. Such an understanding is best crystallized in the idea of wicked problems (Rittel \& Webber, 1973).

Wicked problems, as opposed to 'tamed problems', are best known by the characteristic that they cannot be dealt with in a scientific manner. Table 1 shows the attributes of wicked problems.

\section{Ten attributes of wicked problems}

\footnotetext{
1. There is no definite formulation of the problem. The problem includes a permanent feedback with its environment. The process of formulating the problem is interconnected with the process of its solution.

2. There are no stopping rules. The logic inherent in the problem does not tell you when to stop the inquiry.

3. There are no criteria for correctness. There is nothing in the problem to say how the solution should be judged.

4. There is no immediate test of the quality of the solution.

5. There is no ultimate test of a solution.

6. Once committed to a plan of action, change is consequential. You can't make consequences not happen.

7. There is no list of permissible operations. (If you have a habitual set of actions or prescriptions, try to break out.)

8. There are no well-defined solutions. You either have many solutions or none. The probability that a wicked problem has one solution is null.

9. Every wicked problem is unique.

10. The problem solver has no right to be wrong. Designers are responsible for their work. Unlike scientists, they do not put up work for rejection at a later time.

Table 1 Attributes of wicked problems (Skaburskis, 2008)
}

Wicked problems are associated with complex systems (Zellner \& Campbell, 2015), and clumsy solutions (Hartmann, 2012). Thinking of urban problems as wicked problems is an ontological view that necessitates a certain requirement of theory. When dealing with wicked problems, theory must be able to follow the problem from one section to another, and it also needs to be able to acknowledge the constant change of the problem in relation to its contexts. One example of wicked problems is massive housing projects in post-war American cities that solved the problem of housing demand but created new problems. Theory in this regard must be able to go beyond the set boundaries when the problem moves from one section to another.

Urban design scholars welcomed the idea of wicked problems (Carmona, 2014; Lang, 2005; Verma, 2011). In line with this, Biddulph distinguishes between thinking about and for urban design. Thinking about urban design clarifies the link between urban design and social science, and thinking for urban design must embrace the wicked nature of urban design problems (Biddulph, 2012). Verma considers urban design theories to be 'low theory' because they are dealing with wicked problems (Verma, 2011).

Nevertheless, following the definition of a wicked problem, one may question a few of the attributes in relation to the context of urban design. In particular, the third attribute in Table 1 is problematic as for a long time, urban designers have been trying to find sets of values that measure the success of public places (Whyte, 1980; Lynch, 1984; Jacobs, 1995; Carmona, 2010; Gehl, 2010; Ewing \& Handy, 2009). Such criteria are indeed imperfect. But there are numerous criteria for 
measuring correctness of action and judging their consequences. Also, the general public would notice the enhancement of public places. This contradicts the third attribute of the wicked problem. Problems appear when these criteria are not handled correctly; when they are taken as the final criteria for judgment or when they became too rigid to the extent that one can claim urban design advocates a certain urban form (walkable, mixed use, pre-modern-looking environments, with café culture and local shops) regardless of the existing problems in the context.

Other attributes of wicked problems also need to be treated critically. For example, although each urban design case has its own specific characteristics, some generic mechanisms such as regeneration and gentrification seem to be recurring in different cases (Davison, Dovey, \& Woodcock, 2012; Lees, 2008; Watt, 2013). This would challenge the first and the ninth lines from the list in Table 1. These critiques indicate that instead of accepting wicked problems as a whole package, urban designers must carefully examine the concept of wicked problems, otherwise taking this concept of theory for granted would at risk of dissociating the reality and theoretical works. This leads the article to the next model.

\section{Theory as a subject for critique}

Understanding urban issues as wicked problems enables the professionals to tackle complicated issues. Yet another expectation from working with theory is being able to critically employ it. Dovey and Pafka mentioned that Lynch's theory becomes problematic "when we move uncritically from the question of 'what makes the city legible?' to 'how to make the city legible?'" (Dovey \& Pafka, 2015). But the question is how to critically apply theories.

It seems that there are two meanings for urban critical theories. The specific meaning is an intellectual trend explained remarkably by Brenner as a term that refers to 'leftie' urban thinkers.

"Rather than affirming the current condition of cities as the expression of trans historical laws of social organization, bureaucratic rationality or economic efficiency, critical urban theory emphasizes the politically and ideologically mediated, socially contested and therefore malleable character of urban space-that is, its continual (re)construction as a site, medium and outcome of historically specific relations of social power. Critical urban theory is thus grounded on an antagonistic relationship not only to inherited urban knowledges, but more generally, to existing urban formations" (Brenner, 2009).

This trend of urban thinking is presented in City journal by Rutledge. Critical urban theory asks how urbanism without capitalism and how capitalism without urbanism would be possible. This reading of critical theory is related to urban design if urban designers can be understood as belonging to "associated producers of space" (Goonewardena, 2011).

Despite the strong voice of this trend, critical urban thinking does not necessarily need to be concerned with a certain political view. In fact, following the history of the critical thinking, Frankfurt School's tradition offers a more generic conception of critical thinking. Max Horkheimer, one of the founders of the Frankfurt School, deployed the word critique in his seminal PhD work (Horkheimer, 1982) following Kant's definition of critical concepts as 'concepts whose reach is necessarily and always greater than their grasp' (Buchanan, 2010). Accordingly, concepts such as space, society and community are always and necessarily critical concepts because what one grasps from them is always smaller than the concept's reach. This definition would enable thinkers to avoid reducing critical thinking to any set of understanding (grasps) or to any fixed framework. Although the grasps of critical concepts are needed in making analysis, one must keep in mind that the totality of the concept goes beyond all representations.

This is the generic and broader meaning of critical thinking. There are numerous examples of such critical approaches to urban studies (John Forester, 1980; Dovey \& Fisher, 2014; J. Forester, 
2013; Metzger, Soneryd, \& Tamm Hallstro m, 2016; Purcell, 2013). The generic reading of critical thinking would acknowledge the connections between various issues. Critical thinking, instead of merely focusing on answering the existing questions, asks why this question at this specific point in time is under attention. Critical thinking in this regard cannot be bound to one topic, to one theory, to one context and to one discipline.

By constantly questioning, critical thinking has a particular expectation of theory. Theory in this model is expected to enable questioning, thus it is a subject for critique.

\section{A comparison; various modes of the models}

These four models of different expectations from theory cannot be separated from one another with certain lines. Nonetheless, there are distinguishing core mechanisms for each of them. The following section makes a comparison between the models. Each model takes a different approach when designing public spaces or doing research. In an imaginary scenario, they are compared to one another in this section.

If a designer takes theory as the servant of innovation, they prioritise their inspirations to methodologically studying the context of the designs. A researcher would also start with the answer in their mind and employ theory to justify it.

The designer/researcher seeks new means to enhance their innovation. Their personal understanding plays the major role here. This approach might well be useful in certain cases, for example when the context does not have complex problems and the designer is well experienced. Which designer or researcher exactly falls into this category would obviously be subjective, but the mechanisms are rather independent from the exemplars. At the same time, this approach might be harmful if the innovation loses contact with real problems. Considering theory as the servant for the creativity would also employ theory in order to communicate the design or as a means to justify already established ideas.

If a designer or researcher takes theory in a scientific way, firstly they need to specify according to which theory they are approaching the problem. Following that theory, they then must identify dependent and independent variants. The theory helps to anticipate how the design changes the variants. The designer can then study the result of the design, reflecting either on the employment of the theory in the specific context or on the theory in itself.

Many urban design theories avoid giving a set of dependent and independent variants. Even in the case of Jane Jacobs (Jacobs, 1992) when she calls for her theory to be tested in cities as lab, she consciously avoids suggesting simple correlations between a limited set of factors. This is less the case in Lynch's The Image of the City (Lynch, 1960). It is due to the researcher/designer to pin down the criteria if they expect theory to be scientific. Scientific approach nevertheless would give a robust foundation for improvement of the field. The success of design can evidently be evaluated and lessons from the experience can be added to the tested hypothesis.

If a designer/researcher expects theory to be a means to deal with wicked problems, they would think that reducing the problem to a set of variants is not helpful. The problem can move from one section to another or from one area to another. Thus, scientifically successful cases might be socially disastrous in sections outside of the scope of the given theory. The designer here tries to take the best explanation (Dovey \& Pafka, 2015) that provides the understanding for the specific problem in hand. But what is the best explanation and how has the designer assessed it? And to what extent would the designer/researcher follow the problem? Both questions remain as challenges of this model. When dealing with dynamic and unknown problems, this model is most helpful. 
When designers have a critical approach, they see both the literature and the context as guidelines with a level of uncertainty. Following this model, theory and practice are transformable into one another. When one (either theory or practice) faces a wall, the other steps in. Both theory and practice must constantly be questioned from each other's perspectives. Designing in this manner would be concerned with uncovering forgotten elements. The questioning can go on and on to the level that it loses its touch with the first problem. The challenge here is where to stop questioning. Table 2 concludes the advantages and disadvantages of each model of expectation from theory.

\begin{tabular}{|l|l|l|}
\hline Model of expectation & \multicolumn{1}{|c|}{ Advantages } & \multicolumn{1}{c|}{ Disadvantages } \\
\hline Servant of innovation & $\begin{array}{l}\text { Fast in process } \\
\text { Creates new environments } \\
\text { Adds symbolic value }\end{array}$ & $\begin{array}{l}\text { May not appreciate the context/literature } \\
\text { May repeat mistakes } \\
\text { Does not aim to enhance the existing } \\
\text { knowledge }\end{array}$ \\
\hline Scientific formulation & $\begin{array}{l}\text { In case of failure, what is being refuted would } \\
\text { be open for interpretation } \\
\text { Cannot follow the problem to other areas } \\
\text { Incrementally enhances the knowledge } \\
\text { Easy to teach/communicate with a robust language } \\
\text { Relatively time consuming } \\
\text { Needs adjustments for new cases }\end{array}$ \\
\hline $\begin{array}{l}\text { As means to control } \\
\text { wicked problems }\end{array}$ & $\begin{array}{l}\text { Multi-dimensional } \\
\text { Respects the context } \\
\text { Advanced systematic view }\end{array}$ & $\begin{array}{l}\text { Not clear where to stop following the problem } \\
\text { Not indicating the type of solution } \\
\text { Hard to evaluate } \\
\text { Open to different interpretations }\end{array}$ \\
\hline Subject for critique & $\begin{array}{l}\text { Encourages active assessment of theory for the } \\
\text { problem } \\
\text { Always questions the theory and design } \\
\text { Enhances knowledge } \\
\text { Aims to uncover what the current processes do not } \\
\text { explain }\end{array}$ & $\begin{array}{l}\text { Not clear where to stop following the problem } \\
\text { Prone to be interpreted in different ways } \\
\text { Might be subjective and affected by } \\
\text { professionals' system of beliefs } \\
\text { Time consuming }\end{array}$ \\
\hline
\end{tabular}

Table 2 Advantages and disadvantages of each model of expectation from theory

\section{What is happening in reality?}

The models can be better understood when they face what is happening in real urban design works. Such an interface enables the models to be assessed. The final section of this article examines the four models in relation to a set of interviews with successful urban designers; theorists and practitioners. A set of interviews was conducted with urban designers who have managed to make a distinguishable contribution to the field, in order to investigate their expectations from theory in the field of urban design.

The list of theorists being interviewed here consists of those writers whose texts appear in numerous university reading lists on urban design modules (Foroughmand Araabi 2016). Nine writer were interviewed, all of whom were involved with academia at professorship level. Five were from UK universities two from US and two from Australia. The list of practitioners is a sample of those urban designers whose work appears inspiring to urban design academics, according to an online survey from UCL's (University College London) urban design academicsii. A set of 13 interviews were conducted with these practitioners. The interviews with both groups of theorists and practitioners were conducted from 2013 to 2016 aiming to explore the bigger topic of the indicating factors of the interaction between theory and practice.

From an analysis of the interviews it appears evident that professionals attribute varying meanings when using the term theory, each of which relies on an expectation from theory. The 
predominant group of practitioners expect theory to be normative and demonstrate how to enhance specific aspects of the built environment. In this regard, theory for them is a tool to legitimise their design ideas. Another group emphasise the communicative aspect of theory. Theory eases communicating ideas for professionals.

On the other hand, theorists have different expectations from theory: For one of the theorists, urban design theory should necessarily be related to political economy and social process of making (urban) meanings, otherwise it would not reflect the reality of forces that make cities. Another interviewee understands theory as an updated articulation of history and philosophy. Each generation of professionals must rewrite their theory. A theorist with a research background in theoretical arguments pictures urban design theory as a crystallization of different schools of thought when they face urban problems. One scholar working on the spatial relationship of society and the built environment proposes that theory is a discovery that reveals the spatial logic of societies. The final group of academics considered theory to be a mechanism and structure that explains cities. One participant expected urban design theory to produce generic solutions (types) for urban problems.

The interviews showed that in reality, the professionals use more than one model in their work. The question here is how and when they shift from one model to another. Assessing their experiences of the advantages and disadvantages of each model (in figure 1) enables the professionals to manage their use of any particular model in order to benefit more from the advantages and avoid the disadvantages. Figure 1 shows the number of times each group of interviewees acknowledged different advantages or disadvantages of the models in their experience. The left side of the diagram shows advantages that have been less influential than the disadvantages (right side).

Theory as the servant of innovation has not benefited many professionals. Within the groups who benefited from this model practitioners are represented considerably more than theorists. Those who mention this, think that theory facilitates communication about their work and legitimises their creativity. On the contrary, many theorists criticize this model and point at disadvantages of it; in particular, they mentioned that this expectation from theory disables the progress of the field as theory would not be tested or criticised.

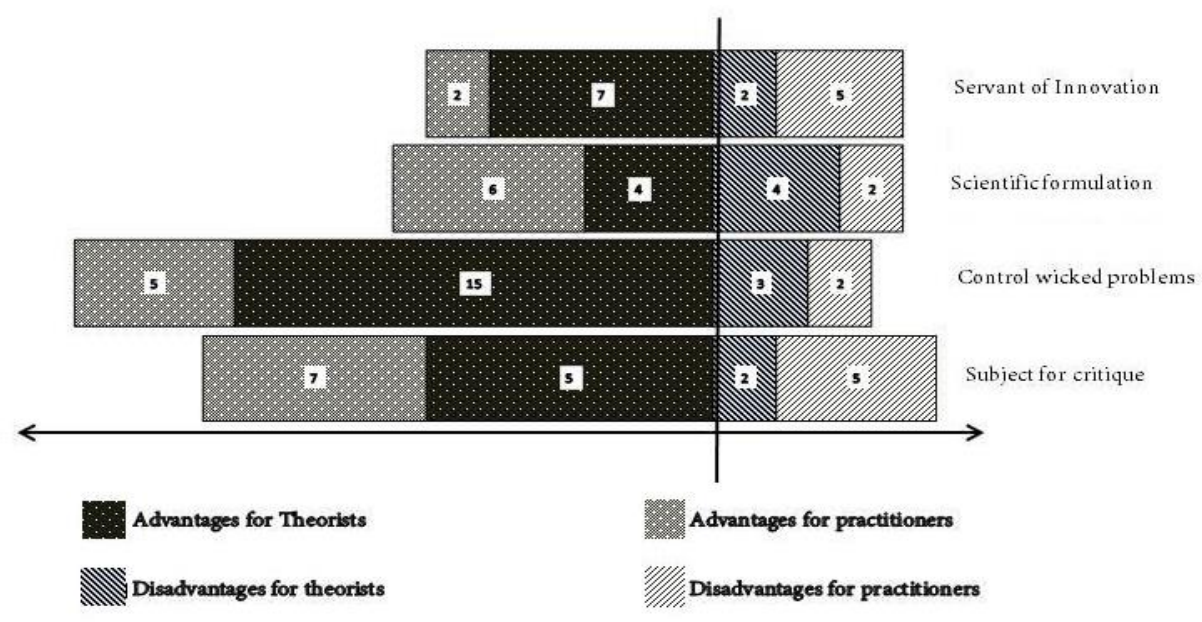

Figure 1 how interviews employ theory

Surprisingly, practitioners acknowledge the positive aspect of theory as a scientific formulation more than academics. This could be explained with the fact that pragmatic theories are more useful than critical ones for practice. Both theorists and practitioners who mentioned the 
disadvantages of this model pointed at it being reductive and irrelevant to real problems. Amongst the four discussed models, theory as means to control wicked problems has been acknowledged the most. This model is the dominant expectation amongst the interviewees. Both groups of theorists and practitioners mentioned all items stated in Table 2 regarding the advantages of this model. However, this model being time consuming and not having clear boundaries to stop analysing are key problems from the interviews.

The fourth model, theory as subject for critique, is perhaps the most controversial finding of the interviews. Practitioners benefit from this model more than the others. Many interviewees from both sides pointed at advantages of this model.

There are two key findings from the interview. First is the fact that the majority of the interviewees acknowledged the advantages of theories. And second, the fact that almost none of them follows only one model of expectations. These findings can be explained in relation to one another.

Professionals being able to employ the right expectation of theory for their problems in hand require a navigation - following Jean Hillier's conception (Hillier, 2011) through models. The key element of this navigation is professionals' ability to choose and move on from one theory to another. "Like military units, they [theories] must be sent into battle at the right moment; and whatever their merits or insufficiencies, they can only be used if they are on hand when they're needed" (Andereotti, 2016, p. 86). This is true for both the topic of each theory (which theory suits the problem) and adapting the right expectation from theory (what are the advantages of the chosen expectation i.e. theory as a means to wicked problems over other models?).

How successful professionals move from one expectation to another (navigation) is not clear. They mentioned experience, knowledge and intuition. From the interviews, it also appears evident that almost all of the interviewees have a critical approach towards the existing body of the literature that could help them to choose the right theory. The academics strongly reject the tendency of taking their texts for granted. They call for more critical assessments of their works. Many theorists criticize the professional circles for not critically evaluating the literature. Some of them point to the need for research-based generation of theory. In turn, practitioners criticised the profession of following 'fixed forms' and "jargonised language".

A professional's ability to employ the appropriate models also indicates the way in which they deal with changes in urban design theory. The data driven understanding of cities, for example Batty's New Science of Cities (2013), interested the practitioners in general. However, some questioned its relevance to practice. One practitioner considered this new theory a "new form of jargonization". Professionals were found to follow the changes in theory and to quickly take a stance.

Urban design theory has scientific, complex, and critical aspects to it. However, not all theories in urban design are expected to follow all characteristics of scientific, complex or critical theories. There is a need for a thinking that enables professionals to shift from one expectation to another. This need merits further discussion, particularly in relation to urban design pedagogy.

\section{Conclusion}

The ongoing debate about the nature of urban design theory confirms the importance of the topic. Scholars seem to disagree over the nature, function and implementation of urban design theory. This article addressed the issue by contrasting what professionals expect from theory and what the purpose of theory is for them. Clearly, what a professional expect from the nature of theory is prior to the subject of any given theory. In reality, professionals deploy theory for different reasons; 
the reasons in this article were conceptualised as professionals' expectations of theory. Analysing the ways in which professionals used the various expectations of theory found that having one overriding expectation limits the possibility of employing the most useful model for any given problem. This article proposes that having multiple expectations from theory enables professionals to benefit to a greater extent from the advantages of each model.

The models presented in this article varied in complexity. For instance, theory as servant of innovation is the simplest model. Thus, its description is relatively brief. The framework presented in this article paves the way for further study as to whether the specific views of the interviewees are related to the particular type of projects they work on.

From the interviews, it became evident that the professionals have multiple expectations from theory. In this regard, the findings do not fit neatly the proposed models. In reality, professionals employ whichever model they find adequate for the problem in hand. This is beneficial to both the professional and to the field, as merely following one model at all times would increase the likelihood of the weaknesses of the approach causing serious problems. This conclusion contributes to the ongoing discussion on the nature of urban design theory as a multiple and dynamic phenomenon.

The categories discussed here should not be seen as solid framework, pigeonholing the literature. In fact, some conceptions of urban design theory cannot neatly fit this framework for example Carmona's idea of urban design as The Place-shaping Continuum (2014). But as the interviews demonstrated, the advantage of the framework is to illustrate the multiplicity of urban design theory and the need for acceptance and working with such multiplicity.

It is important to distinguish between different expectations of theory; their advantages and disadvantages, but at the same time professionals must be able to move from one model to another when necessary. The interviewees in this research seem to be able to do this. Nonetheless, this ability has not been examined and taught systematically. In this respect, This article calls for understanding urban design theory as a multiple phenomenon that constantly moves between models. This would be followed by the educational argument that urban designers need firstly to be familiarised with the idea of the multiplicity of urban design theory and secondly, to acquire the ability to move from one model to another when necessary. This article advocates such changes.

\section{References}

Andereotti, L. (2016). The misery of Theory: on Universality, Contingency, and Truth. In Can Architecture be an emancipatory project? (pp. 72-86). Winchester: Zero books.

Balashov, Y., \& Rosenberg, A. (Eds.). (2002). Philosophy of Science: contemporary readings. London; New York: Routledge.

Banerjee, T., \& Loukaitou-Sideris, A. (Eds.). (2011). Companion to Urban Design. Routledge.

Batty, M. (2013). The new science of cities. Cambridge, Massachusetts: MIT Press.

Bentley, I. (2002). Urban designers as artists. Urban Design International, 7(3-4), 143-152.

Bernstein, R. (1972). Praxis and Action. Duchworth.

Biddulph, M. (2012). The Problem with Thinking about or for Urban Design. Journal of Urban Design.

Brenner, N. (2009). What is critical urban theory? City, 13(2-3), 198-207.

Buchanan, I. (2010). A Dictionary of Critical Theory (1st ed). Oxford: Oxford University Press.

Carmona, M. (2010). Contemporary Public Space: Critique and Classification, Part One: Critique. Journal of Urban Design, 15(1), 123-148.

Carmona, M. (2014). The Place-shaping Continuum: A Theory of Urban Design Process. Journal of Urban Design, 19(1), 2-36.

Curd, M., \& Cover, J. (1998). Philosophy of Science the Central Issues. W.Norton \& Company. 
Cuthbert, A. (2007). Urban Design: requiem for an era - review and critique of the last 50 years. URBAN DESIGN International, 12, 177-223.

Davison, G., Dovey, K., \& Woodcock, I. (2012). 'Keeping Dalston Different': Defending Place-Identity in East London. Planning Theory \& Practice, 13(1), 47-69.

Dovey, K., \& Fisher, K. (2014). Designing for Adaptation: the school as socio-spatial assemblage. The Journal of Architecture, 19(1), 43-63.

Dovey, K., \& Pafka, E. (2015). The Science of Urban Design? URBAN DESIGN International.

Ewing, R., \& Handy, S. (2009). Measuring the Unmeasurable: Urban Design Qualities Related to Walkability. Journal of Urban Design, 14(1), 65-84.

Feyerabend, P. (2002). Against Method. Verso.

Feyerabend, P. (2011). Tyranny of Science. (E. Oberheim, Ed.). Cambridge, UK ; Malden, MA: Polity Press.

Forester, J. (1980). Critical Theory and Planning Practice. Journal of the American Planning Association, 46(3), 275-286.

Forester, J. (2013). On the Theory and Practice of Critical Pragmatism: Deliberative practice and creative negotiations. Planning Theory, 12(1), 5-22.

Foroughmand Araabi, H. (2016). A typology of Urban Design theories and its application to the shared body of knowledge. URBAN DESIGN International, 21(1), 11-24.

Gehl, J. (2010). Cities for People. Island Press.

Giedion, S. (2009). Space, Time and Architecture: The Growth of a New Tradition (Vol. fifth). Harvard University Press.

Godfrey-Smith, P. (2003). Theory and Reality, and introduction to the philosophy of science. The University of Chicago Press.

Goonewardena, K. (2011). Critical Urbanism: Space, Design, Revolution. In T. Banerjee \& A. Loukaitou-Sideris (Eds.), Companion to Urban Design (pp. 97-108). New York: Routledge.

Hall, P. (2002). Cities of Tomorrow (third). Blackwell.

Hartmann, T. (2012). Wicked problems and clumsy solutions: Planning as expectation management. Planning Theory, 11(3), 242-256.

Hillier, J. (2011). Strategic navigation across multiple planes: Towards a Deleuzean-inspired methodology for strategic spatial planning. Town Planning Review, 82(5), 503-527.

Horkheimer, M. (1982). Critical theory: selected essays. New York: Continuum Pub. Corp.

Jacobs, A. B. (1995). Great Streets. Cambridge, Mass.: MIT Press.

Jacobs, J. (1992). The Death and Life of Great American Cities (Vintage Books ed). New York: Vintage Books.

Lakatos, I. (1980). Methodology of Scientific Research Programmes: Philosophical Papers: v. 1. Cambridge University press.

Lang, J. (2005). Urban Design: a typology of procedures and products. Architectural Press.

Lees, L. (2008). Gentrification and Social Mixing: Towards an Inclusive Urban Renaissance? Urban Studies, 45(12), 2449-2470.

Lynch, K. (1960). The Image of the City. Cambridge: MIT press.

Lynch, K. (1984). Good City Form. Cambridge, Mass: MIT Press.

Madanipour, A. (1996). Design of Urban Space, an inquiry into a Socio-spatial Process. Chichester ; New York: Wiley.

Marshall, S. (2012). Science, Pseudo-Science and Urban Design. URBAN DESIGN International, 17(4), 257-271.

Marshall, S. (2016). The Kind of Art Urban Design is. Journal of Urban Design, 1-25.

Metzger, J., Soneryd, L., \& Tamm Hallstro m, K. (2016). 'Power is that which remains to be explained: Dispelling the ominous dark matter of critical planning studies. Planning Theory.

Moudon, A. V. (1992). A Catholic Approach to Organizing What Urban Designers Should Know. Journal of Planning Literature, 6(4), 331-349.

Moughtin, C. (2003). Urban Design: method and techniques. Architectural Press. 
Moughtin, C. (2004). Urban Design: street and square (3. ed., repr). Amsterdam: Architectural Press. Nasar, J. L. (1998). The Evaluative Image of the City. Thousand Oaks, CA: Sage Publications.

Popper, K. R. (2008). The Logic of scientific discovery (Repr. 2008 (twice)). London: Routledge.

Purcell, M. (2013). A New Land: Deleuze and Guattary and Planning. Planning Theory \& Practice, $14(1), 20-38$.

Reynolds, P. D. (2007). A Primer in Theory Construction (Allyn and Bacon Classics ed). Boston: Pearson/AandB.

Rittel, H. W. J., \& Webber, M. M. (1973). Dilemmas in a General Theory of Planning. Policy Sciences, $4(2), 155-169$.

Skaburskis, A. (2008). The Origin of 'Wicked Problems'. Planning Theory \& Practice, 9(2), 277-280.

Verma, N. (2011). Urban Design: an incompletely theorized project. In Tridib Banergee \& A. Loukaitou-Sideris (Eds.), Companion to Urban design, (pp. 57-70). New York: Routledge.

Watt, P. (2013). 'It's not for us': Regeneration, the 2012 Olympics and the gentrification of East London. City, 17(1), 99-118.

Weicher, \& John. (1973). A test of Jane Jacobs' Theory of Successful Neighborhoods. Journal of Regional Science, 13(1), 29-40.

Whyte, W. (1980). The Social Life of Small Urban Spaces. Project for Public Spaces Inc.

Zellner, M., \& Campbell, S. D. (2015). Planning for Deep-Rooted Problems: What can we learn from aligning complex systems and wicked problems? Planning Theory \& Practice, 16(4), 457-478.

\footnotetext{
' Falsifiability is the refutability of a statement, hypothesis, or theory; the inherent possibility that it can be proven false. Many philosophers believe that theory cannot be proved and it does not gain its validity from being tested. In turn, falsifiability indicates the value of theory (Popper, 2008). ii http://www.bartlett.ucl.ac.uk/cross-faculty-initiatives/urban-design/people/academics
} 